\title{
Quality of Life of the Homeless and Restored Women with Psychosis
}

\author{
Upali Dasgupta, Abhiruchi Chatterjee
}

\section{ABSTRACT}

The present study endeavoured to evaluate the quality of life of the homeless and restored women with psychosis. The influence of their living conditions in three different psycho-social milieus and the disability levels on their Quality of Life was also examined. This study was carried out on women clients with psychosis who received medical and psycho-social care under three different programs of Iswar Sankalpa (a Kolkata - based NGO), India. Methods : A matched group design using mixed method technique was adopted for the study. The sample of 50 clients with psychosis was comprised of 16 homeless clients under the Out-reach program, 18 homeless clients under the Shelter home program and 16 previously homeless clients under the Restoration program. The sample was evaluated using the IDEAS and WHOQOL-BREF. After collection of data, statistical analysis was done using the SPSS- version 22. Results : The results mirrored that a statistically significant negative correlation exists between the clients' disability and two domains of QOL, these are- social relationships and environment. Regarding the psychological health and environment domains of QOL, the Shelter home and the Restoration groups significantly differed from the Outreach group. The mildly disabled clients differed significantly from the severely disabled clients in respect to the social relationships domain of the QOL. Conclusion : The knowledge of specific areas of dissatisfaction in QOL of the women with psychosis may haveimplications for the service providers and service planners for more improved medico and psychosocial intervention.

Key Words : QOL- Quality of Life, SZ- Schizophrenia.

\section{INRODUCTION}

The concept of home is at the heart of the term homelessness. The view of homelessness emphasizes the person's alienation and lack of social support networks. Homeless people with psychosis remain homeless for longer periods of time and have less

\section{Corresponding Author}

Upali Dasgupta

Research Wing, Iswar Sankalpa, Kolkata contact with family and friends ${ }^{1}$. Quality of Life measurement in psychiatry has turned into an important outcome in clinical and interventional studies $^{2}$. Although active psychosis may limit the assessment of quality of life, most researchers now acknowledge that evaluation is essential despite limitations ${ }^{3}$. Women's quality of life is heavily influenced by satisfaction with family life, social domains such as family, social relationships, and living situation have the strongest effects. The determinants of quality of life among psychiatrically unwell women differ substantially. Life satisfaction among un-well women is most strongly related to daily activities and financial adequacy rather than social domains ${ }^{4}$. And when women with psychosis become homeless, as Miller and Finery 


\section{Dasgupta, et al. : Quality of Life of the Homeless and Restored Women with Psychosis}

$(1996)^{5}$ stated, they are more vulnerable than other homeless women to 2 be raped, to engage in sexual risk behavior, to have more unwanted pregnancies and abortions, and to be victims of violence during pregnancy. They also are more likely to be unable to meet their children's basic needs and to have lost custody of their children. According to the 2003 U.S. Department of Health and Human Services Report $^{6}$, most homeless persons with mental illness do not need to be institutionalized.... The impact of psychotic disorders is experienced in terms of symptoms, compromised daily living and life achievement activities. The additional impact of homelessness is further cause for concern.

Nowadays, the study of disability associated with psychotic disorders becomes a matter of prime importance. Disability associated with mental illness is a major contributor to the global burden of disease ${ }^{7,89}$. Interventions that promote occupational and social integration raise outcome beyond the level achievable by symptom management alone ${ }^{10}$.

The present article has explored whether living in three different psycho-social milieus has any impact on the quality of life of the homeless and restored women with psychosis. The participants of this study are receiving medical and psychosocial care and support services from three different programs of Iswar Sankalpa (a Kolkata-based NGO). The study has painted a picture of the type of relationships that exist among the four domains of QOL of the clients and their levels of disability. Comparing outcome measures of the clients from the Outreach program, the Shelter home program and the Restoration program (clients restored in their family after prolonged homelessness) will help the organization to evaluate its quality of services. Hence, prioritising the goal-setting and future action planning would be possible.

The present study aimed to i) Assess QOL in clients with psychosis, ii) Observe the correlation between disability and four domains of QOL, iii) Compare the influence of disability levels on different domains of QOL, v) Compare four domains of QOL of the women with psychosis representing three different programs, i.e., Outreach program, Shelter home program and the Restoration program of Iswar Sankalpa (A Kolkata based NGO) under which they are enrolled.

\section{METHODS}

\section{Sample}

Following Purposive Sampling method a representative sample of 50 women with psychosis were selected who have received psychosocial and medical care from three different programs of Iswar Sankalpa. Among them 16 and 18 homeless women with psychosis were selected from the Out-Reach and Shelter Home programs respectively and the rest 16 clients were the women with psychosis who after prolonged homelessness are now restored in their family and continuing under the Restoration program.

Inclusion Criteria : i) Diagnosis of psychotic disorder (F 20-29) according to ICD 10 as diagnosed by the psychiatrists associated with Iswar Sankalpa, ii) Age range:16 years to 60 years, iii) Care from Iswar Sankalpa at least for the last 6 months, iv) Continuing medicine at least for the last 3 months, v) Gender - female.

Exclusion Criteria : i)Non-communicability, ii) Drug/Alcohol dependence. iii) Severe hallucination or delusion at the time of data collection. Iv) Persons with mental retardation, v) Co-morbid psychiatric conditions.

\section{Description of three Programs}

The Out-Reach group : The outreach group as considered under this study consisted of 16 homeless women with psychosis who are enrolled under the Out-Reach (Naya Daur) program of Iswar Sankalpa and are staying on the pavements of Kolkata or under the portico sheds/ flyovers/ plastic sheets or in jhupris or on the railway platforms of Sealdah (within the specified fields of Naya Daur project of Iswar Sankalpa). Here, the social workers of Iswar Sankalpa in association with Psychiatrist and outreach supervisor and outreach counsellor (Outreach service providers' team) intend to target the hardest- 


\section{Dasgupta, et al. : Quality of Life of the Homeless and Restored Women with Psychosis}

to-serve homeless individuals who have a serious mental illness. The goals of the Outreach team is to work for the homeless mentally ill persons and provide them psychosocial care and support services along with medical treatment and enhance the client's community adjustment. One interesting and unique feature of this outreach project is the concept of outreach caregivers. The outreach caregivers are identified from the community itself. The sustainability of the outreach project largely depend on the social worker's and community caregiver's continuous assertive efforts to provide community care services to the homeless mentally ill persons for their rehabilitation, supportive engagement/ employment and finally restoration in their family.

The Shelter Home Group: The Shelter home group as considered under this study consisted of 18 homeless women with psychosis who are enrolled under the Shelter home program of Iswar Sankalpa. The purpose of this Shelter program is to "promote the provision of shelter, psychosocial and medical support services to mentally ill homeless women to enable them to live as independently as possible. After enrolment of the client into this program the residentialstaff, supervisor, counsellors, psychiatrists and other therapists assist the homeless women with mental illness to obtain appropriate supportive services. These services include comprehensive mental health services, maintaining/educating personal hygiene, cleanliness and self-care, medication assistance, counseling and other kinds of psycho-social therapies, supervision, as well as help with independent living skills, such as money management and housekeeping, and other services essential for achieving independent living with dignity. The Shelter is staffed 24 hours per day and psychiatrists are on call during overnight hours.

The Restoration group : The Restoration group in this study consisted of 16 women with psychosis who were previously homeless, but now, are restored in their families and are enrolled under the Restoration program of Iswar Sankalpa. All of these 16 clients were restored from the program of Shelter home. Once the client was restored in her family with the initiatives of the Organization, the action taken by the restoration team that serves to increase the effectiveness and utilization of the previous services is called follow up. The restored clients are followed up in two different ways: firstly, by making phone calls by the restoration officers to the restored client and his/her family members; $\square$ and secondly, the restoration officers personally visit the client's house and have a face to face interaction with the client and family members. The restoration officers make home visits of those restored clients of Iswar Sankalpa who are staying within Kolkata or other parts of West Bengal. or other states of India. A large number of clients from the restoration group are followed up when these clients come to the Shelter home to visit the psychiatrist.

\section{Instruments}

a) A Socio-demographic Characteristics Schedule (developed by the researcher) b) IDEAS: The Indian Disability Evaluation and Assessment Scale (IDEAS) 11developed by the Rehabilitation Committee of the Indian Psychiatric Society. IDEAS quantify disability by relying on information in four core areas of selfcare, interpersonal relationships, communication and understanding and work functioning. c) World Health Organisation Quality of Life BRÈF (WHOQOL Group 1996) 12 is a self -report questionnaire. It contains a total of 26 questions which produce a quality of life profile. Four domain scores: physical health, psychological health, social relationships and environment are analysed. Higher scores denote higher quality of life. It is applicable to people living under different circumstances, conditions and cultures.

Ethics : The principle of informed consent and complete confidentiality was applied. Ethical approval from the Mental Health Research Ethics Committee of Iswar Sankalpa was taken. No physical test was done.

Collection of Data and Procedure Recruitment of the clients to the study started in March' 13 and continued till 30th April' 13. The sample was selected from three different programs of Iswar Sankalpa which 


\section{Dasgupta, et al. : Quality of Life of the Homeless and Restored Women with Psychosis}

represented three different psycho social milieus, i.e., a) the Out-Reach program, b) the Shelter Home program and c) the Restoration program (where the clients are restored in their family or employer's house after prolonged homelessness).

If the inclusion and exclusion criteria were fulfilled, the homeless clients were produced

before the psychiatrists of a government hospital to judge their 'Capacity to consent'. Those homeless women with psychosis who have capacity to consent were counselled to be a part of the study and their consent was obtained. Three patients dropped from the study because they felt exhaustive during the interview and were unable to complete their responses to the WHOQOL-BREF.

Socio-demographic Characteristics Schedule was filled up by the concerned social workers/ counsellors of every client. Disability on account of the illness was assessed through the disability scale (IDEAS). Then the questionnaire WHOQOLBREF was administered to measure the status of quality of life of the participants. As the WHOQOLBREF is a self reporting questionnaire and most of the participants of this study were not sufficiently able to fill up the self-administered questionnaire, the interviewer-administered forms were used following the standardized instructions by the Manual of WHOQOL-BREF.13 Finally the scores so obtained were compared among a) the three different groups, b) the disability levels to establish the causal relationships.

\section{Data analysis}

Statistical analysis was done using the Statistical Package for Social Sciences, version 22 (SPSS-22)14.

\section{RESULTS}

In the total sample of 50 women with psychosis, $32 \%$ are representing the Out-reach group, $36 \%$ are representing the Shelter group and the rest $32 \%$ are representing the Restoration group. Table 1 shows that from the Outreach group the greatest percentage (55\%) of homeless women with psychosis belong to the age range of 36 to 45 years, from the Shelter group the greatest percentage (56\%) of respondents belong to the age range of 36 to 45 years and from the Restoration group greatest percentage (37\%) of respondents belong to the age range of 16 to 25 years. Though, $10 \%$ of the homeless clients from Shelter home are graduates, but majority of the women with psychosis from outreach group (82\%), Shelter group $(72 \%)$ and the Restoration group $(43 \%)$ are illiterate. It also reveals that majority of the respondents are either separated or divorced. Among the clients staying on roads or on Station platforms i.e., the Outreach clients, majority of them are married $(37 \%)$ and $31 \%$ of them are widow. Many of the clients from these three different groups are also unmarried.

Table 2 shows that $50 \%$ of the homeless clients of the Outreach group has no caregiver. When $44 \%$ of the Outreach clients have a community caregiver, all of the Shelter clients $(100 \%)$ and $88 \%$ of the Restoration clients have caregivers. Among the outreach group clients, $50 \%$ respondents have no income. But $44 \%$ of them earn money. Also $83 \%$ of the Shelter respondents earn money. And 63\% of the Restoration group clients earn in terms of Kind. Only $31 \%$ of them earn money by doing some job. Findings of Table 3 shows that majority of the Outreach group clients (56\%) have moderate disability and $25 \%$ have mild disability as rated on the IDEAS. Also, $56 \%$ of the Shelter group clients have moderate disability and $44 \%$ have mild disability. But, $64 \%$ of the Restoration group clients have moderate disability whereas $29 \%$ have mild disability. Correlation studies to measure the relation of Disability and four domains QOL found a statistically significant negative correlation between the clients' disability and their social relationships related QOL $\left(\mathrm{r}=-.329^{*}\right)$ and between the clients' disability and their environment $\left(\mathrm{r}=\mathbf{- . 2 8 2 ^ { * } )}\right.$ related QOL. Comparison of four domains of QOL among the three different groups was done applying ANOVA on SPSS 22. The result showed that the domains of psychological health and environment of the WHOQOL-BREF of the Outreach group differed significantly and in negative direction from that of the Shelter group and the Restoration groups. No 
Dasgupta, et al. : Quality of Life of the Homeless and Restored Women with Psychosis

other difference in the QOL among the three groups was found significant at .05 or at .01 levels.

The mildly disabled clients differed significantly from the severely disabled clients in respect to their social relationships related quality of life. No other finding was found significant.

\section{DISCUSSIONS}

Most of the clients in this study are homeless and only $32 \%$ are restored in their family after prolonged homelessness. In our study, majority of the women with psychosis from Outreach group (82\%); Shelter group (72\%) and Restoration group (43\%) are illiterate. Though, $11 \%$ of the Shelter clients are graduates, but the general trend of attainment of education is much below the matric level. While $44 \%$ clients from the Outreach group, $31 \%$ clients from the Restoration group have some income in terms of cash, the highest percentage of (83\%) clients from the Shelter group earned money for doing Shelter -based income generating activities. In this study, majority of the respondents are either separated or divorced. Among the clients staying on roads or on Station platforms, i.e., the Outreach clients, majority are married $(37 \%)$ and $31 \%$ are widow. Many of the clients from these three different groups are also unmarried. These finding are similar to the findings of many other studies done earlier ${ }^{10,15,16}$. Quality of life and the three groups of Iswar Sankalpa : While comparing the clients from three different programs of Iswar Sankalpa in respect to the four domains

\begin{tabular}{|c|c|c|c|c|c|c|}
\hline \multirow[b]{2}{*}{$\begin{array}{c}\text { Age range } \\
\text { in Yrs. }\end{array}$} & \multicolumn{2}{|c|}{ Outreach Gr. } & \multicolumn{2}{|c|}{ Shelter Gr. } & \multicolumn{2}{|c|}{ Restoration Gr. } \\
\hline & $\mathbf{N}$ & $\%$ & $\mathbf{N}$ & $\%$ & $\mathbf{N}$ & $\%$ \\
\hline $16-25$ & 0 & 0 & 2 & 11 & 6 & 37 \\
\hline $26 \cdot 35$ & 1 & 6 & 2 & 11 & 2 & 13 \\
\hline $36-45$ & 9 & 55 & 10 & 56 & 5 & 31 \\
\hline $46 \cdot 55$ & 4 & 25 & 2 & 11 & 3 & 19 \\
\hline $56-65$ & 2 & 14 & 2 & 11 & 0 & 0 \\
\hline \multirow{2}{*}{$\begin{array}{l}\text { Educational } \\
\text { qualification }\end{array}$} & \multicolumn{2}{|c|}{ Outreach Gr. } & \multicolumn{2}{|c|}{ Shelter Gr. } & \multicolumn{2}{|c|}{ Restoration Gr. } \\
\hline & $\mathbf{N}$ & $\%$ & $\mathbf{N}$ & $\%$ & $\mathbf{N}$ & $\%$ \\
\hline Illiterate & 13 & 82 & 13 & 72 & 7 & 43 \\
\hline Below class IV & 1 & 6 & 2 & 11 & 5 & 31 \\
\hline Class V-Class X & 2 & 12 & 1 & 6 & 2 & 13 \\
\hline School Final & 0 & 0 & 0 & 0 & 2 & 13 \\
\hline HS. & 0 & 0 & 0 & 0 & 0 & 0 \\
\hline Graduation & 0 & 0 & 2 & 11 & 0 & 0 \\
\hline
\end{tabular}

\begin{tabular}{|c|c|c|c|c|c|c|}
\hline \multirow{2}{*}{ Marital Status } & \multicolumn{2}{|c|}{ Outreach Gr. } & \multicolumn{2}{c|}{ Shelter Gr. } & \multicolumn{2}{c|}{ Restoration Gr. } \\
\cline { 2 - 7 } & N & $\%$ & N & $\%$ & N & $\%$ \\
\hline Unmarried & 4 & 26 & 5 & 28 & 4 & 25 \\
\hline Married & 6 & 37 & 3 & 16 & 3 & 19 \\
\hline Separated/Divorced & 1 & 6 & 8 & 44 & 7 & 44 \\
\hline Widow & 5 & 31 & 1 & 6 & 2 & 12 \\
\hline Unknown & 0 & 0 & 1 & 6 & 0 & 0 \\
\hline
\end{tabular}


Dasgupta, et al. : Quality of Life of the Homeless and Restored Women with Psychosis

\begin{tabular}{|c|c|c|c|c|c|c|}
\hline \multirow[t]{2}{*}{ Caregivers } & \multicolumn{2}{|c|}{ Outreach Gr. } & \multicolumn{2}{|c|}{ Shelter Gr. } & \multicolumn{2}{|c|}{ Restoration Gr. } \\
\hline & $\mathbf{N}$ & $\%$ & $\mathbf{N}$ & $\mathscr{F}$ & $\mathbf{N}$ & $\%$ \\
\hline No caregiver & 8 & 50 & 0 & 0 & 0 & 0 \\
\hline One caregiver & 7 & 44 & 0 & 0 & 0 & 0 \\
\hline Two caregivers & 1 & 6 & 0 & 0 & 0 & 0 \\
\hline Shel ter Home Staff & 0 & 0 & 18 & 100 & 0 & 0 \\
\hline Family members & 0 & 0 & 0 & 0 & 14 & 88 \\
\hline Employer & 0 & 0 & 0 & 0 & 2 & 12 \\
\hline Income & $\mathbf{N}$ & $\%$ & $\mathbf{N}$ & $\%$ & $\mathbf{N}$ & $\%$ \\
\hline In Cash & 7 & 44 & 15 & 83 & 5 & 31 \\
\hline In Kind & 1 & 6 & 3 & 17 & 10 & 63 \\
\hline No Income & 8 & 50 & 0 & 0 & 1 & 6 \\
\hline Total & 16 & 100 & 18 & 100 & 16 & 100 \\
\hline
\end{tabular}

\section{Table: 2 shows the percentage of clients from three different groups who get Caregiver's support and have Income.}

of quality of life, the finding showed that the Shelter group and the Restoration group differed significantly from the Out-reach group in respect to their Psychological health related QOL, i.e., their bodily image and appearance, negative feelings, positive feelings, self-esteem, spirituality / religion / personal beliefs, thinking, learning, memory and concentration. The finding also showed that the Shelter group and the Restoration group differed significantly from the Out-reach group in respect to the domain of Environment, i.e., financial resourcees, freedom, physical safety and security, health and social care, home environment, opportunities for acquiring new information and skills, participation in and opportunities for recreation/leisure activities, physical env-ironment (pollution/noise/ traffic/climate), transport. Compared to the Shelter group and the Restoration group, the domains of Psychological health and Environment of QOL of the Outreach group were adversely affected.
This finding is in contrast to the finding of a study which was carried out in Dublin and revealed that individuals with SZ who were living in a hostel or group home had poorer QOL than those who were living independently or with their family ${ }^{17}$. Living conditions and employment are found to be associated with $\mathrm{QOL}^{18}$. Moreover, the social relationships domain of the Shelter group was rated more positively (but not significantly) as compared to the social relationships domain of the Restoration group. This implies that Personal relationships, Social support and Sexual activity facets of the Social relationships domain of WHOQOL of the Shelter group is stronger than that of the Restoration group. A Tasmanian study revealed that family and social relationships are the areas of greatest difficulty for those with $\mathrm{SZ}^{19}$. An interesting finding is that the mean score $(M=41.88)$ of the social relationships related QOL of the Outreach group did not differ much from the mean scores of the social relationships 


\section{Table: 3 Shows the levels of disability of the clients from three different groups:}

\begin{tabular}{|c|c|c|c|c|c|c|}
\hline \multirow{2}{*}{ Disability Levels } & \multicolumn{2}{|c|}{ Outreach Gr. } & \multicolumn{2}{c|}{ Shelter Gr. } & \multicolumn{2}{c|}{ Restoration Gr. } \\
\cline { 2 - 7 } & $\mathrm{N}$ & $\%$ & $\mathrm{~N}$ & $\%$ & $\mathrm{~N}$ & $\%$ \\
\hline Mild & 4 & 25 & 8 & 44 & 4 & 29 \\
\hline Moderate & 9 & 56 & 10 & 56 & 9 & 64 \\
\hline severe & 3 & 19 & 0 & 0 & 1 & 7 \\
\hline
\end{tabular}

related QOL of the Shelter group $(\mathrm{M}=48.75)$ and the Restoration group (M=46.86) and eventually made the mean difference non-significant. This finding reflects that the difference in living conditions of the women with psychosis did not play any pivotal role in determining their social relationships related quality of life. In spite of staying on the streets or footpaths or under the flyovers of Kolkata city, or on the platforms of the Sealdah station, the unconditional social support from the community caregivers and extent of care and concern of the organizational social workers made them fairly satisfied with their social relationships related QOL. This perception of social relationships (domain of WHOQOL) by the Outreach clients has spread a different flavour. Mubarak \& Barber (2003) found that extent of concern of the emotional attachment on the part of the caregiver has been found to increase QOL of the person with SZ who is being cared for. One study found that company and sexual expression lead to improved $\mathrm{QOL}^{21}$. Good social support, in a general sense, has been found to improve QOL ${ }^{22}$. Quality of life and level of Disability The significant and negative correlation between the social relationships related QOL and the global disability scores of the sample concerned indicates that the social relationships facets, like- personal relationships, social support and sexual activity of the women with psychosis under study was seriously compromised by their degree of disability. Again, the Environment related quality of life, like -financial resources-freedom, physical safety and security, health and social care, and the environment of the place where the clients are staying in homeless condition/the environment of the shelter home or the environment of the home where the restored women are staying with their family members, opportunities for acquiring new information and skills, participation in and opportunities for recreation / leisure activities, physical environment (pollution / noise / traffic / climate) and transport are significantly and negatively associated with the degree of disability of the present clients.

In other words, it can be said that the improvement in the social relationships environment related quality of life of the given clients was related to reduction in their degree of disability.

Further, the study has also shown that the social relationships domain of QOL of the respondents with mild disability level differed significantly from that of the respondents with severe disability level. This finding indicates that compared to the clients with mild disability the social relationships related QOL of the clients with severe disability was greatly impaired by their psychotic illness. This finding resembles the finding of some other studies ${ }^{23}$.

\section{LIMITATIONS}

a) The current research sample was not large enough $(\mathrm{N}=50)$ and involved only the women clients with psychosis, but a large number of outreach clients are male who were not included in the study, as a result, may not represent the clients in the community as a whole. The sample size may be regarded as small and hence generalization of our findings to all types of clients is not possible, $b$ ) because of the low literacy level of the present clients, each and every 26 items 


\section{Dasgupta, et al. : Quality of Life of the Homeless and Restored Women with Psychosis}

of the self-reported WHOQOL-BREF instrument had to be explained to the respondents for rating their responses, which might have influenced the actual rating, c) the QOL instrument WHOQOLBREF used in current study is a generic instrument. Using a combination of both generic and specific instrument might have yielded more meaningful results.

\section{CONCLUSIONS}

The most pressing need of the present study was to evaluate the quality of life of the women clients with psychosis enrolled under three different programs of Iswar Sankalpa. Probably, this empirical study is the first of its kind in West Bengal which has conducted research study on the homeless and restored women with psychosis, as there was no well documented research study available in West Bengal of this kind. This is the first scientific research on the three model programs of Iswar Sankalpa. Additionally, the study illuminated rarely considered aspects, i.e., Quality of life of the women suffering from psychosis where most of the clients are homeless. The assessment of Quality of life of the clients and comparing them among the three model programs has allowed a better understanding of clients' quality of life and functional disabilities. This will enable better and more comprehensive monitoring of both medical and psychosocial intervention strategies. Increasingly, this may lead in time to focus on specific aspects of quality of life with the possibility of improved outcomes as a result. This study has also shown that degree of disability has a notably adverse effect on outcome for the clients with psychosis, whereas an ability to maintain social integration and a more 'normal' life course appears to incur a positive effect on outcomes. Keeping personal relationships, having positive social support and also having sexual activity when they feel like, made the outreach group to perceive their social relationships related quality of life positively. The positive strength of this domain of QOL of the homeless women with psychosis under the Outreach program need to be addressed in the future intervention planning. This study has also brought into notice that the social relationships related quality of life of the women clients who were restored in their families (Restoration group) are inferior than that of the women clients of Shelter group. The domain of self-care of the Out-reach group needs special attention for improvement. Considering the present research endeavour as a baseline study, conducting follow-up study on the same sample might have shown better and meaningful direction to the service planners. Longitudinal studies should be carried out to look for correlations between changes in impact (variables) with changes in the levels of disability, modification in the intervention policy in the three model programs, etc. to answer questions regarding causal connections. The resulting picture is complex but it has revealed the multiple problems faced by women clients with psychotic disorders. While some of the difficulties they experience result from impairments inflicted by the disease, other predicaments stem either from insufficient service provision or from the condition of society at large which fails to accommodate these women who are different by virtue of suffering from psychosis. Facing the stark facts which this study reveals should have a salutary effect on decisionmakers, service providers, consu-mers and carers by engaging them in a rational dialogue on how to use more effectively the material and intellectual resources of the organization (Iswar Sankalpa) for the improvement of the quality of life of the homeless and restored women with psychotic illnesses.

\section{ACKNOWLEDGEMENT}

The Research Wing of Iswar Sankalpa is thankful to Navajbai Ratan Tata Trust for providing financial support for this study, to Department of Psychiatry, N. R. S. Medical College and Hospital, to all the participants of this study who despite their life full of distress enriched us by responding to the QOL statements, and to all the social workers of the Outreach Team, Shelter team and to the Restoration Team for their untiring and continuous cooperation during collection of data. 


\section{Dasgupta, et al. : Quality of Life of the Homeless and Restored Women with Psychosis}

\section{REFERENCES}

1. National Coalition for the Homeless, 2201 P St., NW, Washington, DC, 20037; 202/462-4822.

2. Fairclough, D.L. (2002). Introduction. In Des-ign and Analysis of Quality of Life Studies in Clinical Trials. New York : Champan and Hall/CRC; 2002 : 4-15.

3. Barry, M., Crossby, C. \& Bogg, J. (1993). Methodological issues in evaluating mental health services: a review of the empirical evidence. Social psychiatry and psychiatric Epidemiology.

4. Lehman, A.F., and Dixon, L. eds.(1995). Do-uble Jeopardy : Chronic Mental Illness and Substance Abuse. New York NY : Harwood Academic Publishers.

5. Miller, L., \& Finnerty, M. (1996). Sexuality, pregnancy, and childbearing among women with schizophrenia-spectrum disorders. Psychiatric Services, 47, 502-505.

6. Department of Health and Human Services. (2003). American Psychiatric Association. Personal Recovery and Mental Illness : A Guide for Mental Health Professionals, Washington DC.

7. Singh A, Nizamie SH. (2005). Disability : The concept and related Indian legislations. Mental Health Reviews. (2004). Available from URL : http ://www.psyplexus.com/mhr / disability_india.html. Accessed on 13 Septe-mber.

8. Chaudhury, P. K., Deka, K. And Chetia, D. (2006). Disability associated with mental disorders. Indian J Psychiatry. AprJun; 48(2) : 95-101. doi : 10.4103/0019-5545.31597.

9. Sanderson K, Andrews G. (2002). Preva-lence and severity of mental health related disability and relationship to diagnosis. Psychiatr Serv.; 53:80-6. [Pub Med]

10. Jablensky, A., McGrath, J.et.al.(1999). People living with psychotic illness : An Australian study 1997-98 : An overview. Commonwealth of Australia.

11. Indian disability assessment and evaluation scale. (2000). Rehabilitation Committee of Indian Psychiatric Society. Dec.

12. World Health Organization's Quality of Life group (1992) Measuring Quality of Life; Development of the World Health Organiz-ation Quality of Life Instrument (WHOQOL).
13. WHOQOL Group. (1994). Development of the WHOQOL: Rationale and current status. Int JMental Health ; 23:24-56.

14. Statistical Package for Social Sciences, (2013).SPSS Inc. SPSS Base 22.0 for Windows user's guide, version 22 .

15. Thara, R. \& Srinivasan, T.N. (1997). 'Outcome of marriage in schizophrenia', Social Psychiatry \& Psychiatric Epidemiology, vol. 32, pp. 416-20

16. Muller, P., Gaebel, W., Bandelow, B., Kopcke, W., Linden, M., Muller-Spahn, F., Pietzcker, A., Tegeler, J. (1998).'The social status of schizophrenic patients', Nervenarzt, vol. 69, pp. 204-9.

17. Browne, S., Roe, M., Lane, A., Gervin, M., Morris, M., Kinsella, A., Larkin, C., O.Callaghan, E. (1996). 'Quality of life in schizophrenia : Relationship to sociodemographic factors, symptomatology and tardive dyskinesia', ActaPsychiatricaScandinavica, vol. 94, pp. 118-124.

18. Marwaha, S., Johnson, S., Bebbington, P., Angermeyer, M.C., Brugha, T., Azorin, J.M., Kilian, R., Kornfeld, A., Toumi, M. (2008), 'Correlates of subjective quality of life in people with schizophrenia: findings from the EuroSC study', Journal of Nervous \& Mental Disease, vol. 196, 87-94.

19. Holding, T.A., Urbanc, S., Kay, D.W. (1983). `Social outcome after first admission for Schizophrenia in Tasmania. A study of matched pairs', Social Psychiatry, vol. 18, pp. 145-52.

20. Mubarak, A.R. \& Barber, J.G. (2003). 'Emotional expressiveness and the quality of life of patients with schizophrenia', Social Psychiatry \& Psychiatric Epidemiology, vol. 38, pp. 380-4.

21. Bengtsson-Tops, A. \& Hansson, L. (1999). 'Clinical and social needs of schizophrenic Outpatients living in the community : the relationship between needs and subjective quality of life', Social Psychiatry \& Psychiatric Epidemiology, vol. 34, pp. 513-8.

22. Ritsner, M. (2003). 'Predicting changes in domain-specific quality of life of schizophrenia patients', Journal of Nervous \& Mental Disease, vol. 191, pp. 287-94.

23. Kumar,S., Samuel, R.\& Prabhu, R.(1992). Schizophrenia and quality of life in relation to health and illness : Socio cultural issues at world congress of Social Psychiatry, New Delhi. 